\title{
Arquitectura tradicional. Reflexiones sobre un patrimonio en peligro
}

\author{
Juan Agudo Torrico \\ Profesor de Antropología \\ Universidad de Sevilla
}

\begin{abstract}
"No es presuntuoso pensar que tenemos un papel que jugar en la concepción del entorno que vamos a transmitir a las generaciones futuras. Nosotros debemos contribuir a la comprensión de la arquitectura del pasado a fin de preparar unas bases sólidas para el futuro. A decir verdad, este proceso de comprensión debe preceder a todo esfuerzo de documentación en este campo. Se trata de un deber que no debemos tomar a la ligera".
\end{abstract}

J. Bold. Nantes. 1992

La problemática creada en torno a la situación actual y perspectivas de futuro de la arquitectura tradicional o vernácula constituye un ejemplo bastante significativo de algunas de las grandes contradicciones en las que hoy se encuentra buena parte de nuestro patrimonio cultural.

Una situación que, desde luego, no le es exclusiva. Los denominados oficios tradicionales ("artesanías"), rituales, $y$, en gran medida, aquellos bienes que constituyen el patrimonio etnográfico/etnológico comparten situaciones a veces de notable similitud. Forman parte de un "patrimonio menor" o "patrimonio modesto", que con demasiada frecuencia tiene que seguir justificando su existencia frente al otro gran patrimonio que, ya sea por sus valores históricos, estéticos o arqueológicos, no parece ponerse en cuestión su obligada permanencia; frente a, en el mejor de los casos, la mera "conveniencia" de preservar el primero.

No se trata ahora de entrar en la controversia sobre la ambigüedad y variabilidad de las coyunturas históricas por las que el factor tiempo (historia) y determinadas valoraciones morfológicas y/o singularidades (belleza, monumentalidad) se convierten en criterios determinantes para establecer el valor de un determinado bien cultural; de lo que no cabe duda es que estos mismos criterios no se aplican por igual a todo tipo de bienes. Indudablemente no se aplica idéntica consideración al conocimiento de los restos arqueológicos que nos queda de un pasado remoto, que a los testimonios en vías de convertirse en restos arqueológicos de los sistemas de pobla- miento de nuestros campos, y que cobijaron hasta hace una décadas a un considerable número de propietarios y jornaleros andaluces; pese al papel que han desempeñado los modos de vida generados en torno a los sistemas de trabajo y producción agroganaderos en la historia andaluza en un tiempo no demasiado lejano, y la influencia que ello ha tenido en nuestra cultura. Como tampoco se aplica igual consideración a las cuidadas construcciones, ya sean palaciegas o grandes casas más o menos influenciadas por los estilos arquitectónicos urbanos de turno, que acogieron a la oligarquía terrateniente andaluza, y al resto de las viviendas que habitaron la otra inmensa mayoría de la población andaluza; sin olvidar que también esas grandes casas tienen un notable valor etnológico, como testimonios del poder e influencia de este sector tan significativo y determinante de la estructura social andaluza durante centurias, por lo que no hay que apreciar únicamente sus singularidades históricomo-numentales.

La comparación entre unas y otras arquitecturas no es sólo cuestión de porcentajes, como si la arquitectura tradicional más modesta careciera de valor; demostrándose en la práctica de los trabajos de campo que la diferencia entre lo culto y lo popular no es sólo el resultado de la imagen mixtificada que también en este caso impondría la cultura dominante, sino que expresaría un gradiente real en cuanto al interés de la primera frente a la desvalorización de la segunda. Todo lo contrario, cualquier estudio que se aproxime a esta otra arquitectura, va a resaltar precisamente su riqueza de matices, su diversidad y capacidad expresiva, resultante de las innumerables variables a tener en cuenta: diversidad ecológica de las regiones andaluzas (materiales, orografía y adaptaciones climáticas), experiencias histó-

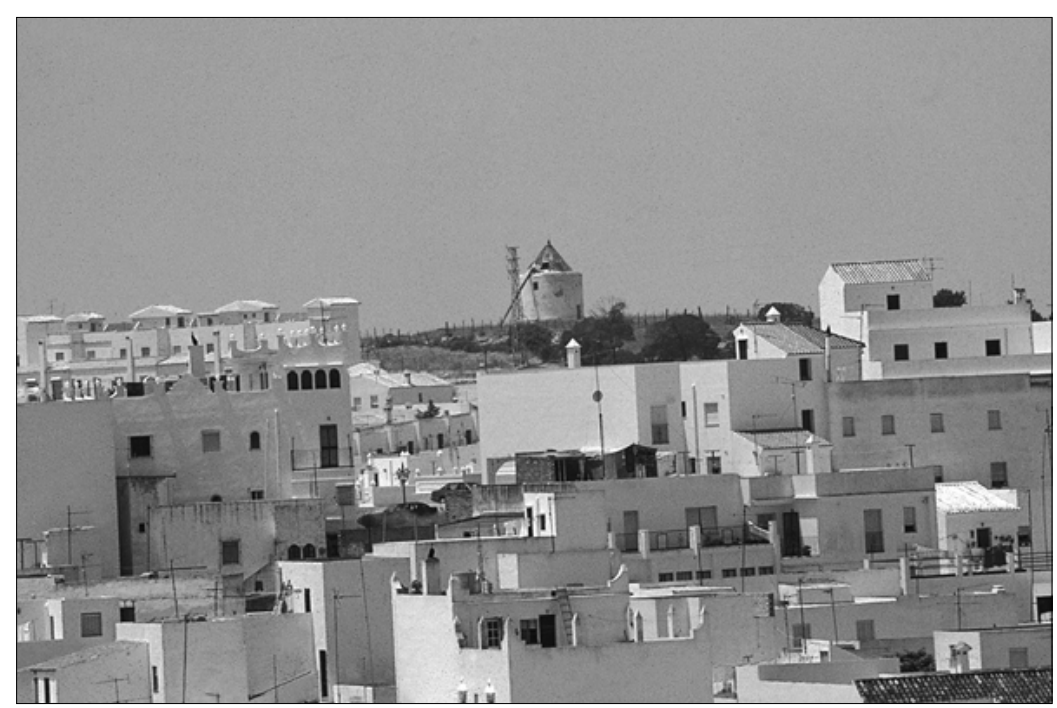




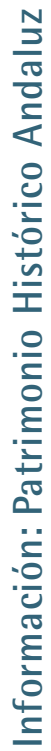

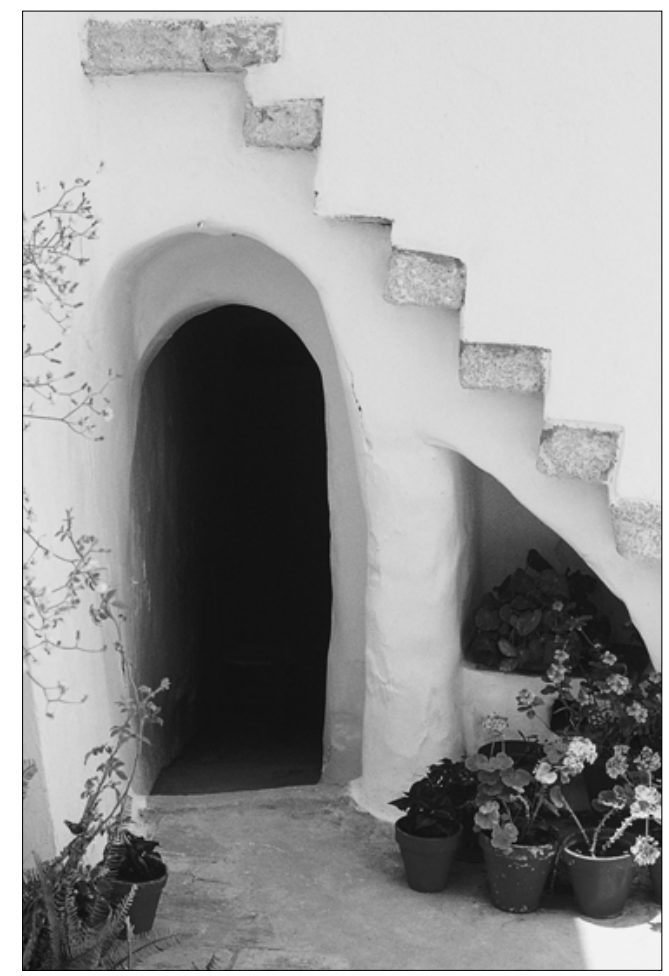

ricas (técnicas constructivas, planificación urbanística, organización y características de los espacios construidos, usos sociales y significados simbólicos de los mismos), diversificación de actividades productivas y adaptaciones de los espacios construidos, y, no menos significativo, las diferencias internas que se han dado entre los grupos sociales que han conformado la estructura social andaluza (jornaleros, proletariado urbano, pelentrines, artesanos).

Consideraciones respecto al reconocimiento de su valor cultural que no tienen que ver necesariamente con otras problemáticas en relación con sus posibilidades o imposibilidades de conservación: abundancia, dificultades de adaptación a nuevos usos, sacralidad del principio de propiedad y disponibilidad de

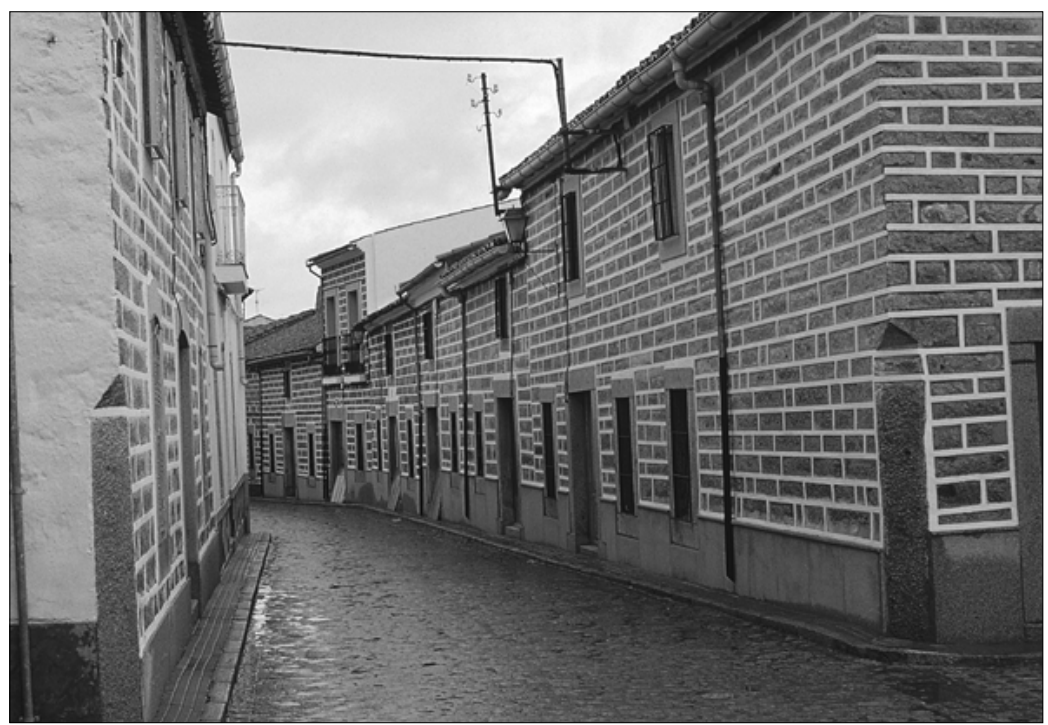

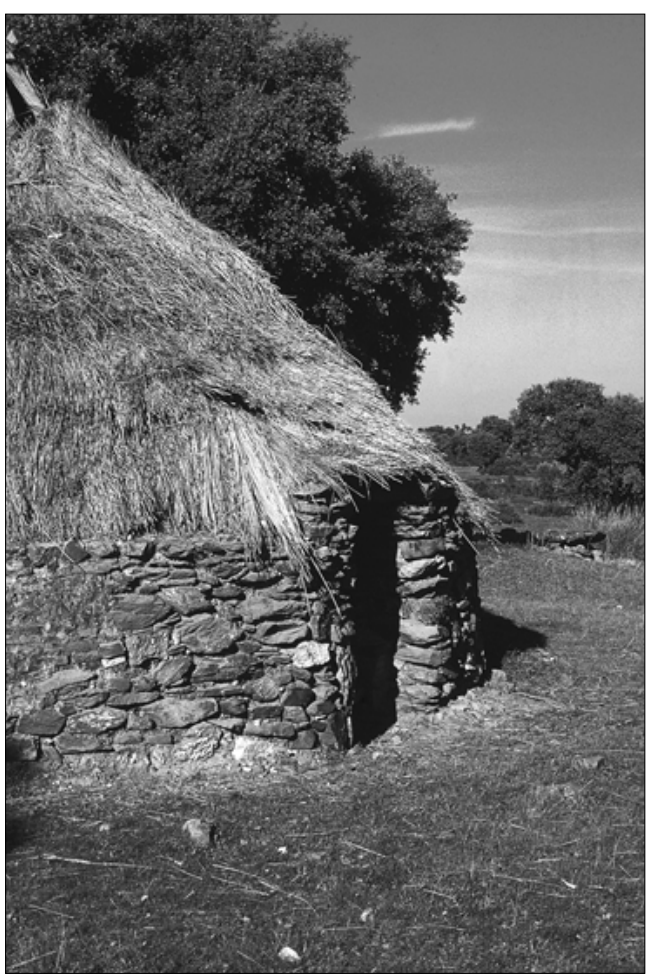

sus dueños, etc. Por el contrario, la compleja problemática que por estas y otras razones análogas, todas ellas derivadas en buena medida de su condición de patrimonio vivo que conserva en muchos casos la función primigenia para la que fue concebido, no debe hacernos olvidar la desconsideración que se ha tenido hacia esta arquitectura hasta fechas no muy lejanas (ihasta hoy?). Viejos textos como la Carta de Atenas de 1931, tan valorada como punto de partida del trato respetuoso que debiera darse a los restos arqueológicos y grandes monumentos del pasado, no tuvieron igual consideración con la innombrada arquitectura tradicional (aunque también es verdad que para entonces aún se estaban levantando edificaciones y empleando técnicas constructivas que hoy forman parte de esta categoría precisamente por haber caído en desuso), tenida más en cuenta como contexto para ensalzar dichos monumentos que como texto cultural en sí misma.

Una apreciación, su sentido contextualizador ya sea para recrear los "entornos monumentales" o para reproducir las imágenes arquetípicas de nuestros pueblos, que en buena medida se sigue manteniendo; valorándose fundamentalmente una apariencia externa cada vez más estandarizada (véanse los reglamentos recogidos en las normas subsidiarias de las diferentes poblaciones) para crear estos ambientes teatralizados. Pero que aún no ha dado lugar a otro tipo de estudios y planes de actuación más sistemáticos, según se aprecia en la escasa y parcial literatura científica con la que contamos hoy para conocer en detalle estas arquitecturas andaluzas.

Aunque esta limitación en la escasez bibliográfica sobre el tema cuenta con algunas excepciones, con frecuencia bastante reiterativas en sus contenidos, muy 

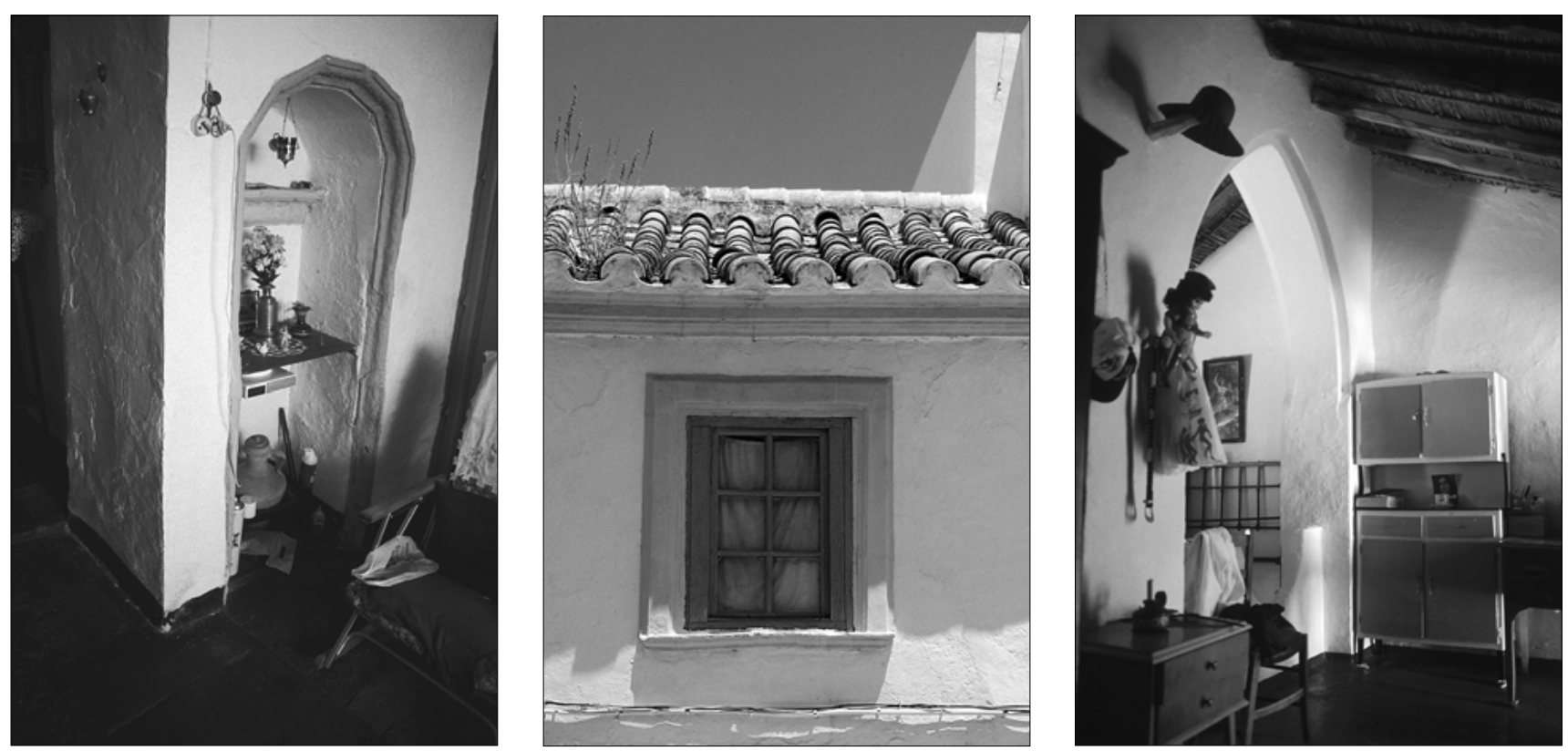

significativas por cuanto hacen referencia a aquellas tipologías que tanto nos recuerdan algunos de los rasgos más folcloristas con los que se ha venido identificando a Andalucía desde el s. XVIII y XIX: ya sea la prístina evocación del pasado musulmán que nos manifiesta la arquitectura alpujarreña (ésta y no otra como la de las comarcas de los Filabres y valle del Almanzora almerienses o la Axarquía malagueña); o el "primitivismo" del hábitat en cuevas de las provincias granadina y almeriense, que tanto llamaron la atención de los viajeros románticos precisamente como ejemplo explícito de la posición que ocuparía Andalucía en la evolución de la cultura (y, dentro de ella, como imagen de la situación del colectivo étnico gitano), cuando este tipo de hábitat ni fue siempre tan marginal, ni, desde luego, exclusivo de la etnia gitana. Temáticas, en razón de su interés documental, a las que hay que sumar, complementando en cierta medida las imágenes anteriores, la de otro tipo de arquitectura capaz de recrear, visualizar, la otra cara de la moneda que conformó la estructura social andaluza: los grandes cortijos y haciendas. Si bien, en este caso, el interés por este tipo de arquitectura ha venido precedido por su cuestionamiento como parte de la arquitectura "popular/tradicional", de manera que pasaran a formar parte del interés, metodología de análisis, y valoraciones como bienes culturales a la vieja usanza; y, de este modo, una vez considerados como edificios monumentales/singulares, va a ser su condición de testimonios histórico-artístico-monumentales lo que determine su valoración; con lo que son perfectamente asumibles como dignos objetos de estudio por parte de las disciplinas que se autorrogan las prioridades de intervención sobre el gran patrimonio cultural.

A fin de cuentas, como las otras grandes obras histórico-artísticas, la funcionalidad productiva de estas edificaciones (como la religiosa en los templos, o la habitacional en los palacios) es simbólicamente secundaria frente a su condición de edificaciones emblemáticas

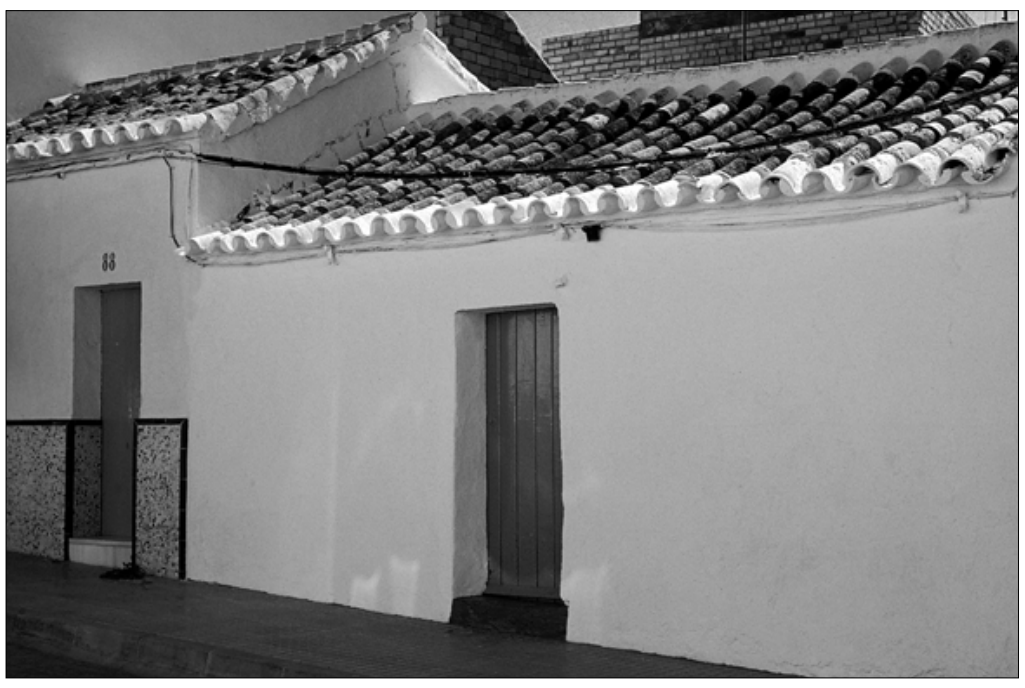

que testimoniaron el poder económico y social de sus propietarios, sólo así se explicaría no sólo la importancia de los señoríos, jardines y capillas, que poco tienen que ver con la funcionalidad que se le supone a una edificación agroindustrial de estas características, sino también el empleo de materiales nobles y depuradas y costosas técnicas constructivas en espacios que hubieran podido ser resueltos de manera más sencilla. Todo ello explicaría que a la hora de analizar y documentar esta arquitectura, de establecer prioridades en cuanto a los "elementos nobles" a conservar o a no modificar, se reserve esta condición para los jardines, señoríos, capillas, torres y miradores, seguido en importancia de los espacios que acogieron a los diversos elementos implicados en los procesos de trabajo que se dieron entre sus muros, pero rara vez quedan reflejados los espacios que ocuparon las gañanías, caseros, apeadores, jornaleros, o molineros. Por último, en otros casos, como es el relativamente reciente interés por documentar $y$, en la medida de lo posible reconstruir/restaurar e "incluso" mantener en funcionamiento viejos 
Gráfico 1. Inmuebles inventariados.

Espacios cuyo uso preferente sea la producción, la habitación o la sociabilidad

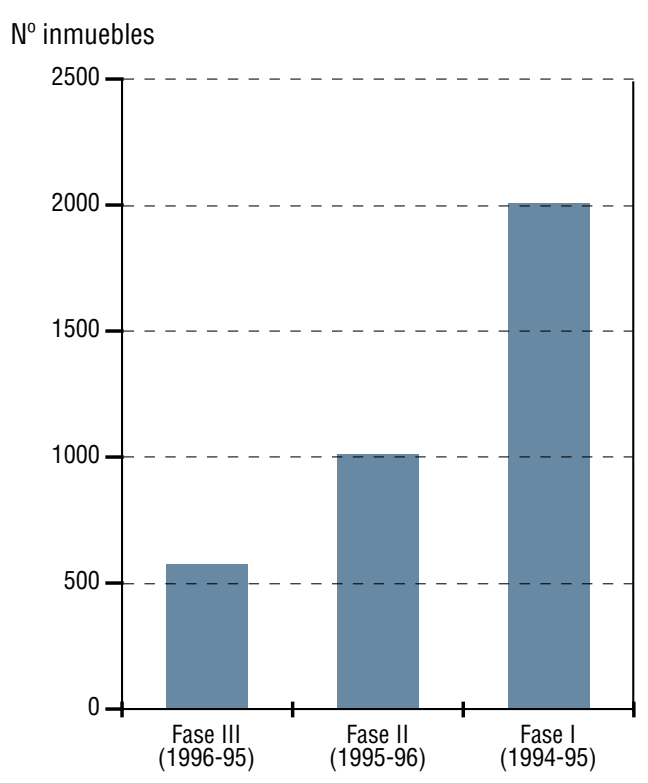

ingenios industriales, molinos hidráulicos o norias, las razones vienen a ser otras: son construcciones donde el paso histórico del presente al pasado, de la funcionalidad originaria al desuso, se ha consumado, pero aún podemos reconstruir su historia sin recurrir a viejos textos sino a la información oral de quienes trabajaron y vivieron en ellas. Se trataría, siguiendo una preocupante estandarización de los referentes materiales, en nuestro caso arquitectónico, de seleccionar unos pocos de estos vestigios del pasado que satisfagan el consumo de tradición que reclama nuestra sociedad actual. Los molinos hidráulicos se llevarían la palma en el interés de estos trabajos; además de contar en muchos casos con el añadido de su antigüedad centenaria y monumentalidad, son modelos privilegiados para recrear esta idealización de un pasado de románticas autenticidades (la calidad no residiría el producto/objeto resultante sino el método empleado en su producción o elaboración) que también tiene que ver con la extensión hasta este tipo de arquitectura, en esta ocasión sí reconocida como "popular", del interés por disciplinas como la arqueología ("arqueología industrial") que están progresivamente reclamando prolongar su campo de acción hasta el presente.

De las otras arquitecturas (talleres y oficios artesanales, arquitectura del agua, viviendas urbanas incluyendo no sólo la arquitectura popular sino también el estudio de las grandes casas construidas por la alta burguesía, viviendas y construcciones auxiliares diseminadas por nuestros campos, arquitectura minera, etc.), con desigual fortuna según provincias y comarcas, la información y conocimiento del que disponemos se va diluyendo poco a poco, hasta ser prácticamente inexistente en el caso de muchas de estas tipologías e incluso de territorios completos. Y sin embargo, lo que nos queda de este patrimonio forma aún un vasto legado que reclama una mayor atención. Aunque cada vez es más frecuente usar tiempos verbales en pasado para referirnos a un patrimonio que mengua día a día.

Las razones de que ello esté ocurriendo se amparan con demasiada frecuencia en el fácil argumento de la imposibilidad de conservarlo todo; unas argumentaciones que no se sostienen cuando se observa y conocen los mecanismos especulativos o de desidia de los que se sirve una aparente selección natural que poco tiene que ver con la hipotética neutralidad de toda dinámica cultural.

\section{UN PATRIMONIO DESCONOCIDO Y ESPECIALMENTE AMENAZADO}

El problema es aún más grave cuando inclusive desconocemos las características y contenidos del patrimonio que se está destruyendo. No debiéramos esperar a una futura metodología arqueológica, o a preguntar a otras fuentes indirectas que hayan podido conservarse, para saber acerca de lo que aún podemos observar mediante un somero trabajo de campo, y conocer en detalle sus contenidos y significados hablando directamente con quienes aún recuerdan o conocen las técnicas constructivas empleadas para levantarlos, y pueden detallarnos los usos y funciones que tuvieron.

Por múltiples razones, nos encontramos en un tiempo de transición donde el presente, con un vertiginoso ritmo de cambio, se diferencia ya de un pasado cercano no sólo en clave temporal, sino cultural; pero es también un tiempo de transición donde la pérdida de función y desuso de estos viejos espacios arquitectónicos no significa que también hayan dejado de formar parte de nuestra memoria colectiva. Todo lo contrario, lo que fueron y para lo que sirvieron sigue formando parte de la memoria viva de unas generaciones bastante próximas a la nuestra, por lo que, siempre que no sea posible su preservación, al menos nos debe quedar el conocimiento y relación detallada del significado que han desempeñado estas arquitecturas, como parte destacada entre el conjunto de referentes, de rasgos culturales, que han contribuido a establecer nuestras señas de identidad.

Sin olvidar que ni antes ni ahora estas arquitecturas pueden desligarse de los modos de vida de las que han formado parte. Desvincularlas de estos contextos es dotarlas de un aparente valor por sí mismas que está suponiendo, en unos casos, extender la vieja imagen de monumentalidad-singularidad a nuevas tipologías antes desconsideradas (véase al efecto la polémica acerca del intento, imposible jurídicamente, de declarar determinados inmuebles a la vez como monumento y lugar de interés etnológico), y en otros, proyectar sobre estas edificaciones unos idealizaciones romanticistas bastante cuestionables en muchos casos: determinados patios y corrales de vecinos, añoranzas ecologistas de viejas formas de hábitat diseminadas por los campos. En ambos casos, el resultado, a la vez 
Gráfico 2. Inventario de Arquitectura Popular. Fase I.

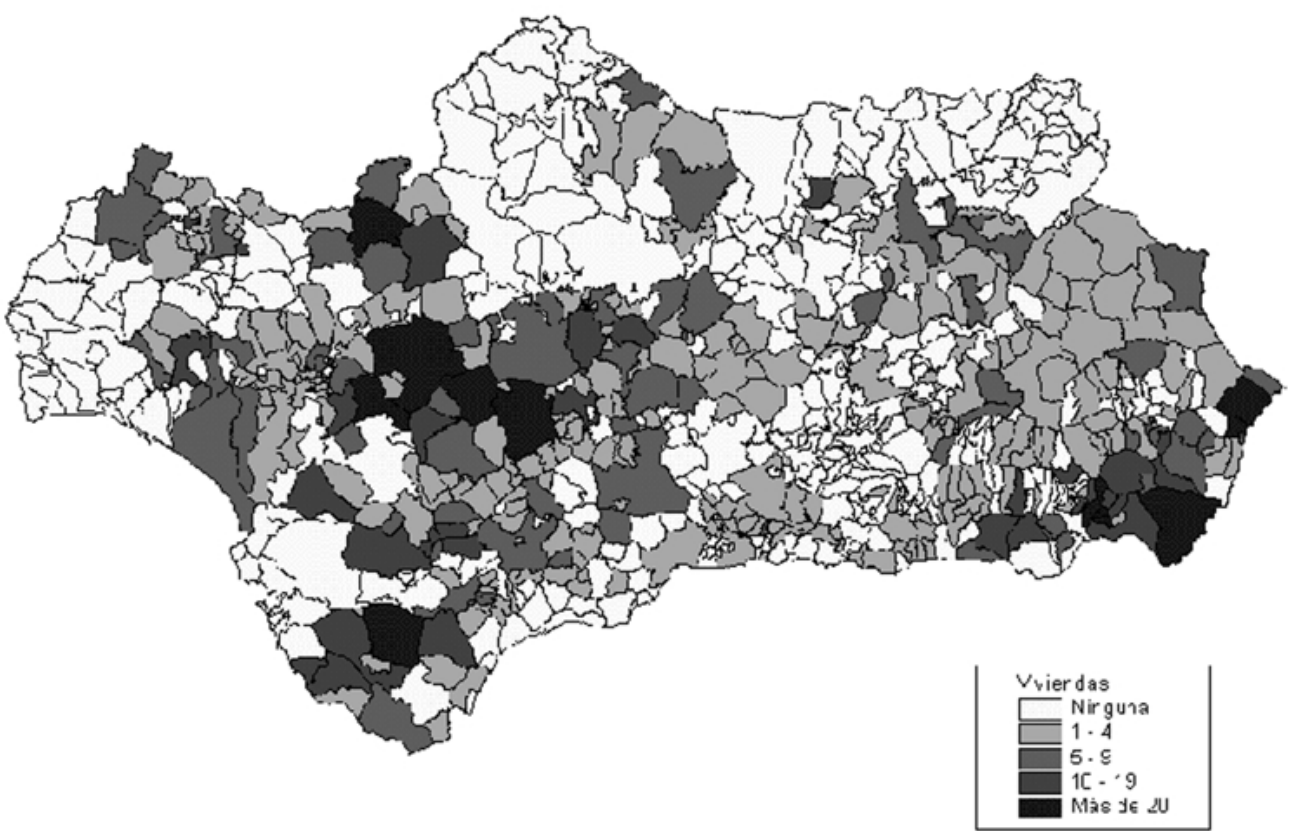

que se hace aún más difícil perfilar los antiguos límites del sentido de lo que es y no es "arquitectura popular" y los valores intrínsecos que se le supone, es el establecimiento de una nuevas lecturas más o menos monumentalistas y de singularismos ahora que es necesario "completar" el cuadro patrimonialista con su parte de etnografía, para lo cual es preciso seleccionar que parte de dicho patrimonio debe representarlo; sólo que esta selección pocas veces se establece a partir del conocimiento detallado de dicho patrimonio.

La propia documentación se convierte así en un medio fundamental para la protección de nuestro patrimonio cultural: conocer y documentar como punto de partida para poder establecer los criterios adecuados de intervención y protección. Aunque en no pocas ocasiones esta documentación es en sí misma el modo más adecuado, cuando no el único, de proteger nuestro patrimonio, quedando como testimonio del fin último que debemos dar a este vocablo: su condición de manifestaciones de lo que han sido unas formas propias de actividades productivas, relaciones sociales, creencias y valores, sean cuales sean los medios en los que se materializan, entre ellos la arquitectura.

Al contrario de lo que pudiera pensarse, cuando se mal interpretan los términos de tradición y pasado, no todo lo que fue puede ni debe conservarse. Consideración que nos vale para cualquier dimensión de la cultura; entre las que la arquitectura, una vez más, se nos muestra especialmente elocuente por su consideración de soporte testimonial de unas muy precisas relaciones sociales y condiciones de vida. Así, si de lo que hablamos es de los chozos y chozas tan abundantes en un pasado aún no demasiado lejano, por mu-

\section{Gráfico 3. Distribución de tipologías. Edificios de producción y transformación}

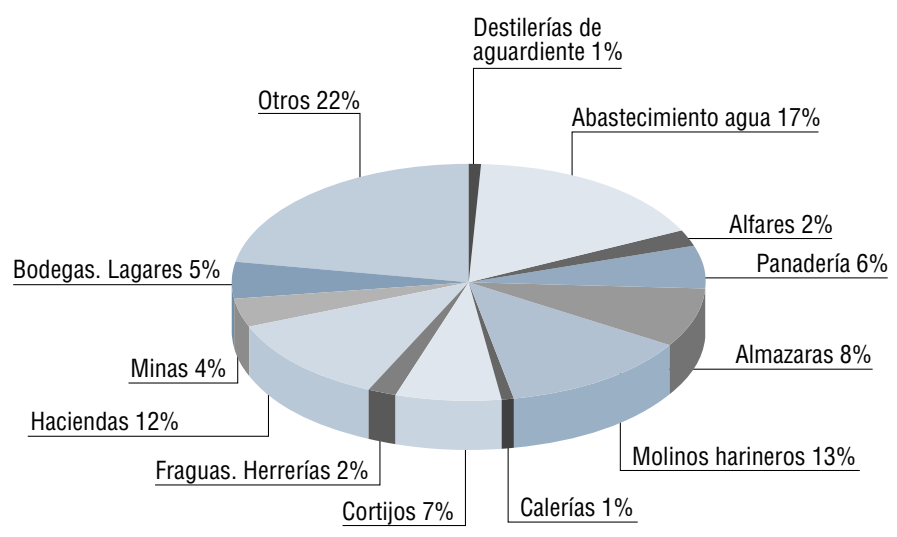

cho que queramos ver en ellos, sobre todo en los antiguos chozos de casal con bases circulares de mampostería cuyas ruinas todavía son perceptibles en Sierra Morena, una pervivencia de remotas, y también diríamos que ecológicas, formas de hábitat, su desaparición no debe considerarse como "pérdida" cultural si de lo que hablamos es de las condiciones de vida que tuvieron los pastores y sus familias que vivieron en ellos. Otro tanto podríamos decir de las tribunas levantadas para uso de vendimiadores y aceituneros, de las infraviviendas urbanas de muchos jornaleros de limitados espacios y calidades constructivas, o de buena parte de los hoy exaltados corrales de vecinos construidos ex profeso para ser habitados por un proletariado urbano. Sólo en algunos casos de entre los ejemplos que acabamos de poner (patios de vecinos) 
se podrá mantener su aspecto externo, mejorando sus condiciones de habitabilidad, para preservar su principal valor como espacios culturales: sociabilidad y relaciones de vecindad que se ha dado entre los vecinos que los habitan. Pero en otros casos, tal y como estamos diciendo, únicamente debe preservarse su memoria documentada y, a lo sumo, aplicar una metodología museística para la conservación/reconstrucción de algunos ejemplares que rememoren sus técnicas constructivas, distribución y función de los espacios creados, etc. Cualquier otra pretensión (recordemos al efecto la polémica sobre la pérdida de "autenticidad" e idealizaciones sobre la pax vecinal que todavía se escucha en el caso de los patios de vecinos que han sido reformados y con ello garantizado su pervivencia) sería muy cuestionable, salvo que también pretendamos conservar las mismas condiciones de vida para las que fueron concebidos; o peor aún, que pretendamos convertir a edificios y vecinos en parte de las nuevas estampas neofolclóricas al uso, y que, curiosamente (?) de forma tan obsesiva se tienden a asimilar con aquellas otras decimonónicas.

Sin embargo, estas y otras muchas excepciones que podamos encontrar no nos valen para hacer extensible a toda la arquitectura tradicional el mismo inexorable destino de destrucción y sustitución. Es el caso de otro tipo de construcciones de diversa índole, incluidas las viviendas de los sectores sociales intermedios (y aún de las propias familias jornaleras según en qué comarcas e incluso localidades), que han caracterizado a la sociedad andaluza desde el siglo XIX, tanto en los ámbitos rural como urbano; y que sorprenden en muchos casos por la calidad de las técnicos constructivas empleadas, disponibilidad de espacios, y posibilidades de readaptación.

\section{¿Disfuncionalidad y/o cambio de valores?}

Aunque nos vamos a seguir refiriendo fundamentalmente a la arquitectura habitacional, buena parte de lo que estamos diciendo puede aplicarse a cualquiera de los campos en los que queramos dividir metodológicamente la arquitectura tradicional.

La presencia de estos testimonios culturales es muy frecuente que origine unos sentimientos y reacciones ambivalentes; entre su reconocimiento -no necesariamente valoración positiva- como testimonio cultural de un pasado que ha llegado hasta nuestros días, y su consideración como bienes de libre disposición sometidos únicamente a intereses privados- frente a los que "nada podemos hacer"-, por lo que, al contrario de lo que ocurre con el tratamiento que reciben los otros referentes arquitectónicos declarados monumentos históricos, deben someterse a la dinámica de los nuevos cambios urbanísticos, o desaparecer por mero abandono, sin que se tenga en cuenta la primera de las valoraciones referidas. Es más, incluso llega a considerarse que cualquier pronunciación en su defensa irá recubierta del aura de una folclorización contraria a la evolución "natural" de todo proceso cultural; aunque, en sentido contrario, sí sea signo de moderni- dad cualquier defensa propagandística que pueda hacerse en favor de los nuevos modelos culturales, aún cuando respondan a intereses muy concretos que poco tienen que ver con la supuesta evolución natural, impredecible, de los usos culturales.

A decir verdad, toda comparación entre unas y otras arquitecturas, entre las obras encuadrables entre los cultos monumentos histórico-artísticos y las modestas construcciones que forman la arquitectura popular/tradicional, siempre será relativa. Las primeras cuentan con el beneplácito de todas aquellas condiciones que originaron precisamente esta valoración, y que, con demasiada frecuencia, son razones que han tenido y tienen que ver con la condición de estos referentes arquitectónicos como manifestaciones privilegiadas de los valores de la ideología dominante de turno: escasez, singularidad en su diseño o valores estéticos, monumentalidad, pertenencia a alguno de los grandes estilos arquitectónicos, autoría destacada... En consecuencia, van a ser los que acaparen los siempre escasos recursos destinados a garantizar su preservación, de acuerdo con la concepción más tradicional del término conservación.

Por el contrario, la otra arquitectura tradicional, no siempre ha tenido cabida dentro de las miradas sobre el patrimonio cultural. Hasta fechas aún no muy lejanas no se reconocerá que "La noción de monumento comprende la creación arquitectónica aislada así como también el sitio urbano o rural que nos ofrece el testimonio de una civilización particular, de una fase representativa de la evolución o progreso, o de un suceso histórico. Se refiere no sólo a las grandes creaciones sino igualmente a las obras modestas que han adquirido con el tiempo un significado cultural" (Carta de Venecia, 1964). Hasta entonces, bien pudiera decirse que "no existía", o en el mejor, o peor, de los casos únicamente era tenida en cuenta, tal y como hemos indicado, si contribuía a realzar aquella otra arquitectura.

Sea como fuere, la arquitectura tradicional no se considera que esté revestida del aura de monumentalidad de la primera, y se supone que no es tan escasa; aunque irónicamente se pueda pasar de la abundancia a la total extinción con la rapidez de la que han hecho y hacen gala un considerable número de poblaciones andaluzas (véanse en los años setenta las poblaciones costeras malagueñas y hoy en día las gaditanas y almerienses) sin que tampoco ello alarmara a nadie. Por el contrario, otros valores contrastivos serían más cuestionables, aunque tampoco han sido tenidos en cuenta. Así, por ejemplo, podríamos considerar bastante discutible la singularidad de la arquitectura "culta", frente a la tradicional. La repetición estilística, artesanal en muchos casos, de la que hacen gala las grandes construcciones de estilo, y que rebasan sin problemas viejos y nuevos límites fronterizos entre territorios y Estados, contrastaría con esta otra arquitectura tradicional vinculada a espacios ecológicos y territorios históricos muy concretos, lo que hace que se caracterice, precisamente, por su singularidad y diversidad: tipologías y técnicas constructivas, diseños espaciales, elementos ornamentales, léxico 
Gráfico 4. Inventario de Arquitectura Popular. Fase II.

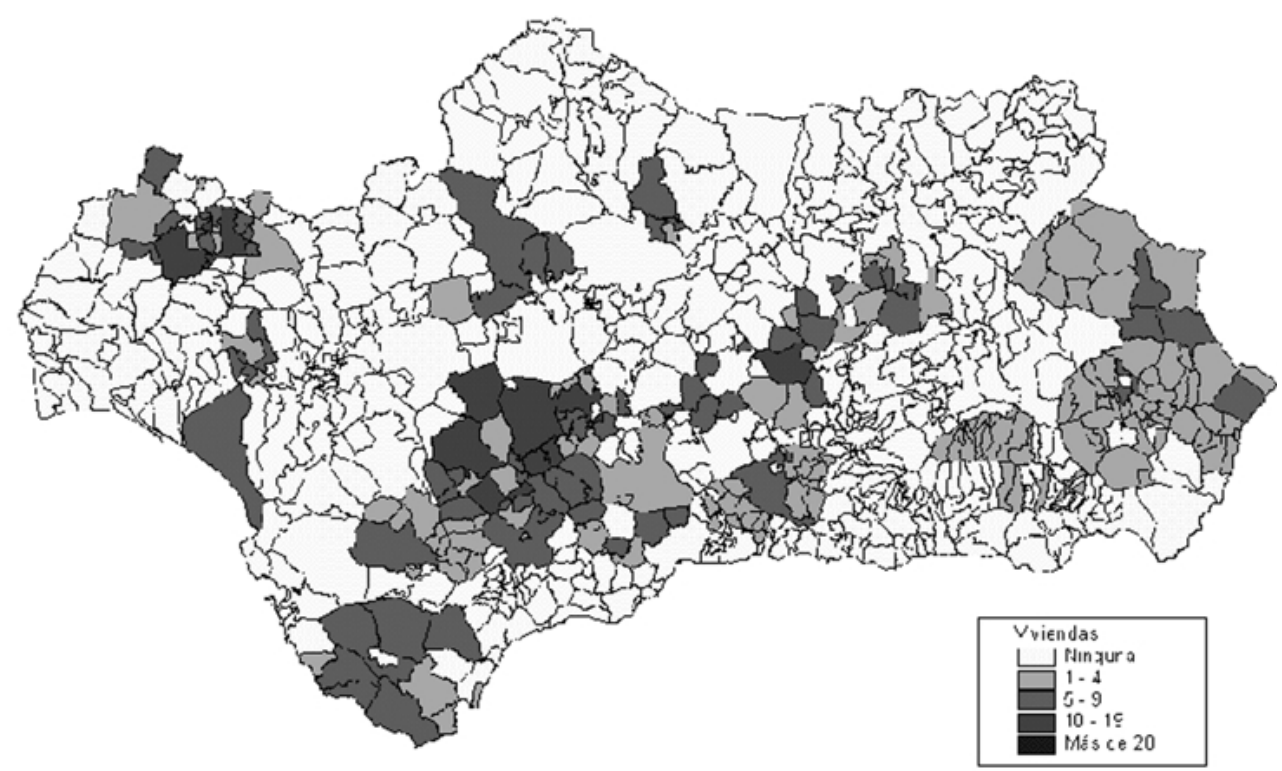

empleado, valores simbólicos atribuidos a los diferentes espacios, etc. De ahí la frecuente inclusión de este tipo de arquitectura entre los rasgos culturales más relevantes que contribuyen tanto a identificar y distinguir a unos colectivos étnicos de otros, como para analizar la propia diversidad interna que se da dentro de los mismos: baste como ejemplo las diferencias que podemos apreciar con sólo recorrer las diversas comarcas andaluzas.

Pero tal vez la principal diferencia entre unas y otras arquitecturas provenga de su valor de uso y de la diferente consideración del factor tiempo/historia. Mientras que la primera forma parte de un concepto tiempo interpretado, generalmente, en clave de pasado, la segunda formaría parte de una concepción del tiempo que no es del todo histórico, en un doble sentido: bien porque se mantienen sus funciones primigenias, con las consiguientes readaptaciones al compás de las nuevas condiciones de vida (viviendas), o porque el tiempo en el que fueron abandonadas las actividades que les dieron vida (procesos de producción y transformación, almacenaje, alojamientos públicos, etc.) forman aún parte de la memoria viva de quienes las conocieron en uso e incluso participaron de las mismas, o bien de generaciones precedentes muy próximas a las actuales.

En razón de ello, tal vez el error consista en intentar aplicar a uno y otro tipo de patrimonio similares criterios de "conservación" y "valorización". Cualquier medida que se deba aplicar a la arquitectura tradicional debe tener en cuenta el propio uso social continuado que se da a este tipo de bienes culturales, invirtiendo la valoración del mismo, desde una perspectiva negativa a otra positiva; no haciendo sino continuar el largo proceso histórico de continua re-

\section{Gráfico 5. Distribución de tipologías. Viviendas}

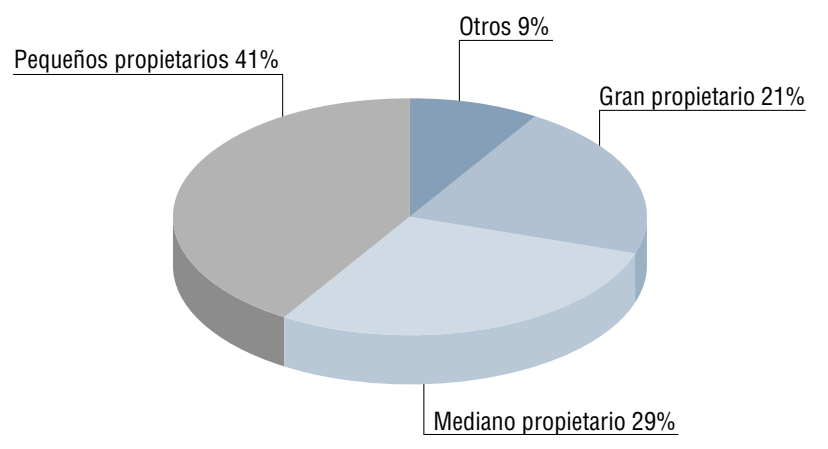

semantización cultural al compás de los cambios de funciones. Afirmación pensada principalmente para la arquitectura habitacional, pero que también puede valer para otro tipo de edificios relacionados con las más diversas actividades productivas, y que como bien demuestra la historia particular de muchos de ellos, lejos de permanecer inmutables desde sus orígenes, han ido evolucionando en usos y reacondicionamientos sin quebrar con ello su integración en los entornos urbanos o rurales en que se encuentran. Pensemos en las transformaciones y nuevos usos, impredecibles hace apenas unas décadas, de algunas de estas edificaciones valoradas ahora por sus propias características arquitectónicas y destinadas a las más diversas funciones (turismo rural, segundas residencias, actividades productivas alternativas); o el cambio de actitud de las instituciones públicas hacia este tipo de edificaciones y su consiguiente readaptación para usos sociales antes reservados a palacios y templos abandonados (museos, centros culturales, etc.). 


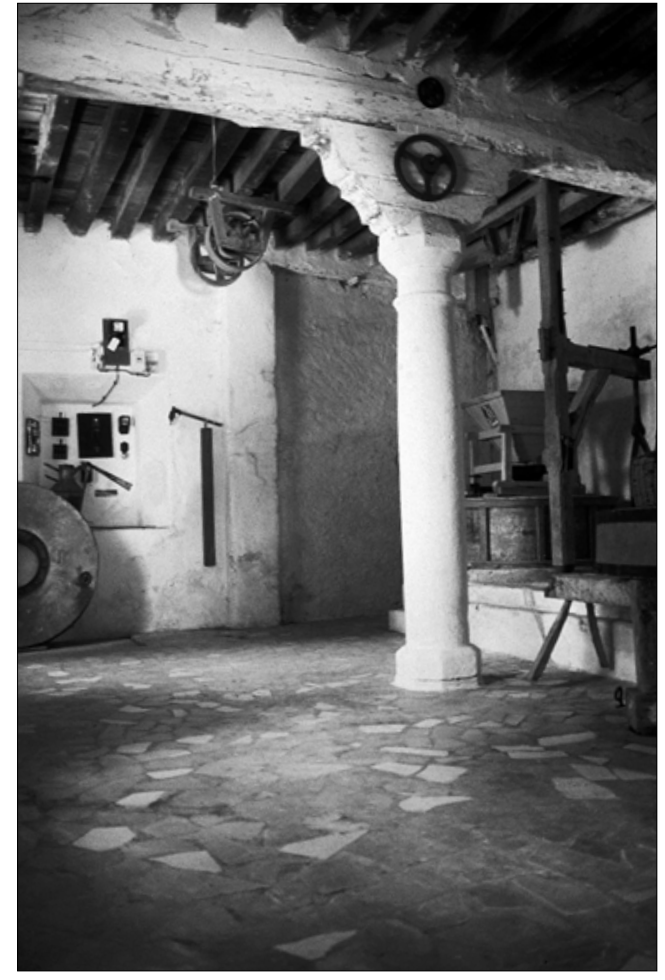

De hecho, en la destrucción de una buena parte de la arquitectura habitada, late, detrás de lo que se considera es una mejora de la calidad de la vivienda o creación de nuevos espacios urbanos, la implantación de unos nuevos modelos arquitectónicos y de uso de los espacios construidos que en muchos casos habría que cuestionar en cuanto a los resultados finales.

La propia destrucción es con demasiada frecuencia un sinsentido, si tenemos en cuenta que en muchas viviendas, la desaparición de las viejas prácticas agroganaderos ha dejado libre más del $60 \%$ del espacio disponible (soberaos, cuadras, corrales, pajares, etc.), con las consiguientes enormes posibilidades de readaptación; dado que en estos casos tampoco se trataría de una conservación a ultranza de estos espacios disfuncionales, sino de su reintegración como espacios habitacionales. $Y$ ante estas circunstancias, su preservación va más allá de la mera documentación: hace falta toda una política de concienciación y de flexibilización de los proyectos para la rehabilitación de estas viviendas y espacios arquitectónicos, que eviten la imposición de modelos únicos, y se adapten a las realidades concretas de cada localidad/comarca.

Aunque en este futuro próximo, indudablemente incierto, no todo parece ser negativo. Tal vez entre sus nuevas posibilidades de supervivencia esté la circunstancia de que en la "nueva valoración" de esta arquitectura del pasado, en su concepción tanto de los espacios cerrados como abiertos, se sustentan parte de las argumentaciones que están poniendo en entredicho los modelos de transformación urbana que se siguen; y que han hecho, y siguen haciendo, estragos en poblaciones que ni siquiera están acuciadas en cuanto a problemas de suelo urbanizable, dimensiones de sus cascos históricos, etc. Y, por otra parte, las propias administraciones públicas empiezan a jugar un papel destacado en los intentos de control sobre las acciones particulares (y públicas) que se siguen sobre esta parte de nuestro patrimonio cultural; aunque también es verdad que habría mucho que decir sobre la propia imagen que se tiene por parte de la propia administración sobre dicha arquitectura tradicional, orden de prioridades a la hora de protegerla, o las medidas reales que se ponen en práctica para hacerlo.

Sin embargo, no debemos olvidar que cualquier medida administrativa que intentara imponer la conservación inmodificable de todo lo que nos queda, sería, además de imposible, inapropiada; por lo que supondría de un falso inmovilismo cultural. Por el contrario, se trata de que sean los propios agentes sociales los que generen una nueva resemantización de los espacios creados. De hecho, se está dando una notable paradoja en algunos de los casos en los que se atisba una emergente conciencia en las actitudes de preservación e incluso recuperación de la arquitectura tradicional. La dependencia, principalmente de las poblaciones rurales de los conceptos de vivienda impuestos desde los principales centros de producción cultural estandarizada que representan los centros urbanos más destacados -y formalización disciplinar de las técnicas y proyecciones arquitectónicas-, se está invirtiendo en muchos casos: el rechazo a la idea de "casa" que imperó hasta hace una década muestra hoy una creciente inversión, observable incluso en la nueva "recreación" urbana de lo que supuso este modelo tradicional de hábitat, y lo que significa tanto en su proyección de espacios interiores como de ocupación de espacios colectivos.

Al mismo tiempo, el valor añadido aplicable a las viviendas conservadas por su antigüedad y "autenticidad", como una manifestación más del consumo de tradición tan en boga, comienza a constituir un factor a tener en cuenta. Sobre todo a partir, y de ahí la paradoja, de la creciente demanda de estas viviendas que se está dando, generalmente como segunda residencia, entre ciertos sectores de las poblaciones urbanas. El cambio radical, aplicado a los mismos elementos y espacios arquitectónicos, del concepto negativo de "viejo" por el positivo de "antiguo", ha supuesto reconsiderar el valor de muchos de estos elementos como ejemplificadores del buen hacer del pasado: condiciones ambientales creadas, materiales empleados (cuando el transcurso de un breve plazo de tiempo ha desmontado algunos de los mitos acerca de la "eternabilidad" de los nuevos materiales y técnicas constructivas, que, por lo demás, en lo que tienen de positivo, también pueden ser aplicables a la conservación de esta arquitectura tradicional, mejorando algunos de sus aspectos más negativos, como puedan ser los sistemas de cubiertas); valoración de la distribución interna y su racionalidad; e incluso la aplicación desde el presente hacia el pasado de nuevos valores por descubrir, tales como el cambio de significado de los gruesos muros de estas casas, antes ejemplo de derroche en materiales y espacio, y hoy también ejemplos de técnicas constructivas sólidas y capacidad de 
aislamiento y privacidad, frente al anhelo que actualmente se tiene de estos mismos valores en las nuevas construcciones y espacios urbanos. Buen ejemplo de esto último sería lo que está ocurriendo con la recuperación del hábitat de cuevas en las poblaciones del norte de las provincias de Granada y Almería, como son Guadix, Galera, Castillejar, Cuevas de Almanzora, etc.; o el valor, incluido el de rentabilidad económica, -atracción de turismo-, que se está dando al patrimonio arquitectónico "popular" en determinadas comarcas, como es el caso de la gaditana Sierra de Grazalema o la onubense Sierra de Aracena.

\section{A modo de conclusión:}

La arquitectura tradicional debe ser interpretada, antes que nada, como testimonio privilegiado que nos habla de la riqueza y diversidad de la cultura andaluza.

Por "arquitectura tradicional" o "vernácula" entendemos el modo en que unos materiales, generalmente extraídos del entorno natural, y técnicas constructivas, adquiridas bien por procesos evolutivos endógenos o por préstamos culturales, han servido para dar respuesta a las necesidades físicas y sociales de un colectivo, generando modelos arquitectónicos -técnicas constructivas, diseños espaciales y resultados estéticos-, con unos logros originales en razón de la experiencia histórico-cultural y adaptaciones ecológicas propias de cada territorio. Nos interesa cómo han resuelto dichas necesidades las poblaciones del territorio andaluz, empleando los recursos naturales disponibles, pero seleccionándolos y elaborándolos para crear un hábitat adaptado a las necesidades socioeconómicas -junto a otras funciones culturales de carácter más simbólico-, de quienes las han habitado. La diversidad de sus modelos debe reflejar la diversidad interna de la estructura social y económica andaluza. De ahí que, sin entrar en este momento en una mayor precisión, dentro de esta arquitectura tengan cabida tanto los modelos más humildes de las viviendas jornaleras, como las grandes casas de la clase terrateniente andaluza, por cuanto reflejan la totalidad de la estructura social andaluza, y han dado lugar a un complejo juego de imitaciones, y antonimias de gran riqueza cultural.

Por todo ello, la arquitectura tradicional no es una mera "expresión material", con valor en sí misma de acuerdo con los criterios estéticos o arquitectónicos que queramos atribuirle: su valor radica en su condición de verdaderos textos documentales, que nos hablan del pasado y del presente, de la evolución de una colectividad, de cómo ha resuelto sus necesidades materiales y espirituales, y de cómo se han articulado los diferentes sectores sociales que la han conformado en el marco de relaciones sociales muy concretas.

Recorriendo las calles de cualquiera de las poblaciones andaluzas, o mientras cruzamos por sus campos, cualquier observador medianamente avezado, recibirá una buena lección de historia: grupos sociales que componen dicha sociedad, sistema de propie- dad imperante, sistemas de aprovechamientos que se han dado en el medio rural, etc. Las poblaciones y los campos se convierten en escenarios muy concretos, donde percibir y contrastar todo este juego de relaciones habidas entre los hombres y entre éstos y su entorno natural. De este modo, viviendas de grandes propietarios convivirán con las de pelentrines o jornaleros, aunque ocuparan diferentes espacios de acuerdo con los propios valores de centralidad-periferia que se de al entramado de sus pueblos, antiguas almazaras convertidas en carcasas vacías en espera de nuevos usos o de su definitiva desaparición, con cualquier otro tipo de nuevos edificios destinados a las más diversas funciones, viejas tabernas con modernas cafeterías, etc. se entremezclaran en un tejido arquitectónico que nos muestra así el continuo trajinar desde el pasado al presente.

Condicionantes ecológicos e históricos se han dado cita para establecer las similitudes y disimilitudes que caracterizan y diferencian a la vez a unas poblaciones de otras, a unas comarcas de otras; hasta componer el cuadro que convierte a estas manifestaciones arquitectónicas en una parte significativa y relevante de las expresiones culturales que diferencian a unos colectivos étnicos de otros.

La lectura que hagamos de ella no debe hacerse al margen de las otras grandes arquitecturas cultas. En el imaginario del discurso que se pretende hacer sobre Andalucía, ambos tipos de patrimonios arquitectónicos van unidos: la Mezquita junto a las blancas casas de la judería cordobesa, la Alhambra de Granada junto a las callejuelas del Albaicín, los grandes monumentos arquitectónicos junto a las vistas de los blancos caseríos de nuestros pueblos; aunque la realidad del valor asignado a uno y otro tipo de patrimonio siga siendo muy dispar.

Su preservación pasa por un definitivo cambio de actitudes ante la misma: tanto por parte de la administración que ha de articular unas medidas coherentes destinadas a su valorización y conservación,

Fotos: Juan Agudo Torrico

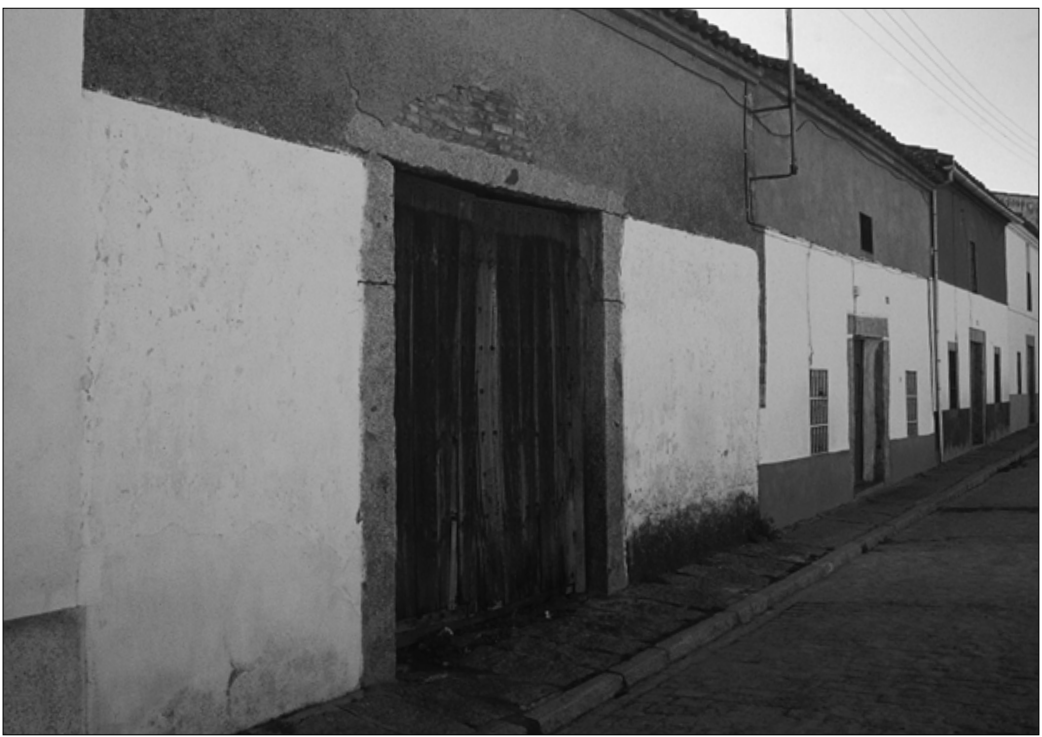


como, no menos importante que lo anterior, por el cambio de las actitudes y valoraciones negativas que en muchos casos persisten entre quienes las siguen habitando.

Se trata de modificar las propias valoraciones colectivas hacia un tipo de patrimonio arquitectónico considerado durante décadas como inexistente (sólo lo monumental era patrimonio), y en el peor de los casos incluso como negativo. No olvidemos que, para muchas poblaciones, este tipo de arquitectura sigue siendo el exponente de su pobreza, de ahí que no deba extrañarnos la agresividad con la que simbólicamente han sido transformadas o se siguen destruyendo las viviendas de los sectores sociales tradicionalmente más dependientes de nuestra sociedad: cambiar la casa aunque sólo sea en su imagen externa (ejemplo significativo de Alcalá del Valle en la provincia de Cádiz) ha sido manifestar el cambio de estatus propiciado por un mayor nivel de rentas económicas. De ahí, significativamente, el destino que se daba a los primeros ingresos obtenidos con la emigración, o la situación actual de destrucción generalizada observable en poblaciones jornaleras como las de la Sierra Mágina jienense o la Sierra Sur de Sevilla, cuando otras fuentes de ingresos permiten embarcarse en viviendas desmesuradas que pueden tardar varios años en construirse.

La arquitectura tradicional andaluza, pese a su siempre recurrente presencia entre algunas de las imágenes más tópicas y estandarizadas sobre "lo andaluz", sigue siendo una gran desconocida.

La imagen propagandística que se hace de la arquitectura tradicional como una de nuestras referencias culturales más significativas va unida al desconocimiento real que tenemos de ella, y a la situación de enorme riesgo al que está sometida. Sobre esta arquitectura tradicional confluyen todas las posibles causas que acentuarían su extinción: desde la especulación urbanística que -encubierta en muchos casos con el aura de la necesaria renovación modernizadora, y potenciada con demasiada frecuencia desde las propias instituciones municipales que debieran velar por este patrimonio- la está erradicando de todo centro urbano donde se dé un cierto dinamismo económico a todas las demás causas internas emanadas de los profundos cambios habidos en la historia reciente de Andalucía y que han dejado, de un año para otro, obsoletos buena parte de las tipologías arquitectónicas tradicionales, o partes muy significativas de las construcciones que se mantienen en uso: lagares, almazaras, cortijos, eras, caleras, lavaderos, fuentes públicas, fondas y ventas, etc. - los doblados/soberaos, cuadras, corrales, pajares, etc. en el caso de las viviendas que siguen habitadas.

Sin embargo creo que existen otros problemas que dificultan precisamente la articulación de unas medidas coherentes que pudieran contribuir a la preservación de esta parte tan significativa de nuestro patrimonio etnológico, como es el desconocimiento de la realidad en que se encuentra y de la gran diversidad de nuestras comarcas. En muchos casos, los tópicos homoge- neizadores sustituyen a una realidad donde no siempre se dio la blancura sempiterna de las fachadas e interiores de la viviendas, el inevitable patio, o a la existencia en toda casa que se precie de unas buenas rejas donde sujetar las correspondientes macetas de geranios.

Lo malo es que estamos también haciendo que la realidad actual se empareje cada vez más con estas imágenes esperadas, potenciando en muchos aspectos una arquitectura neofolclorista (de nueva planta o tras las consiguientes reformas de la que se conserva), como esencia de una arquitectura cuya existencia como un patrón único que abarcaría a todos los territorios y clases sociales andaluzas nunca existió. Cuando no, como ya dijimos, sigue existiendo una clara desproporción respecto al interés por aquellas manifestaciones arquitectónicas que más se han relacionado con los modelos de pueblo andaluz-cultura-arquitectura, que mejor se adecuaron a las tendenciosas imágenes románticas de la Andalucía de los viajeros europeos de los siglos XVIII y XIX.

Y sin embargo la diversidad de nuestra arquitectura tradicional es uno de los principales activos de nuestro patrimonio etnológico. Tan pronto como nos adentremos en el recorrido de las comarcas andaluzas, son tantas las excepciones a cualquier modelo, que precisamente es esta diversidad la que se convierte en norma. Podríamos citar, como se ha puesto de manifiesto en el desarrollo del Inventario de Arquitectura Popular promovido por la Consejería de Cultura, arquitecturas tan singulares como las viviendas de la comarca centro-occidental de la Sierra Norte de Huelva, la arquitectura abovedada del cordobés Valle de los Pedroches, la arquitectura "negra" de techos de pizarra de la Sierra de Los Filabres almerienses, las peculiares viviendas a veces rehundidas y normalmente organizadas en torno a pequeños patios de luz de la comarca del Marquesado del Zenete granadino, y, cómo no, las tan conocidas viviendas de las Alpujarras granadina y almeriense y las viviendas de cuevas, que no sólo son, como muchos creen, propias y poco menos que exclusivas de la población de Guadix o del Sacromonte granadino, sino que forman vastas barriadas de un considerable número de pueblos del norte de Granada y Almería.

Pero también tenemos que hablar de la diversidad de estas manifestaciones en cuanto a tipologías. La misma crítica que hay que hacer respecto al modelo esquemático de lo que sería "la" casa andaluza, la podemos hacer respecto a lo que es representativo de la otra arquitectura tradicional no habitacional: además de las consabidas almazaras, haciendas, cortijos y molinos harineros, se nos olvidan que en nuestros campos y pueblos hay también tahonas, eras (a destacar el conjunto de varias poblaciones del marquesado de Zenete y muy concretamente el de Huenejar), caleras (pensemos en el paraje de Morón de la Frontera o las impresionantes construcciones de las caleras de La Calahorra en Granada), lavaderos (véanse los conjuntos de la Sierra de Huelva y de la comarca de los Vélez almerienses), soberbios sistemas hidráulicos, barriadas formadas por construcciones vinculadas a 
Gráfico 6. Inventario de Arquitectura Popular. Fase III.

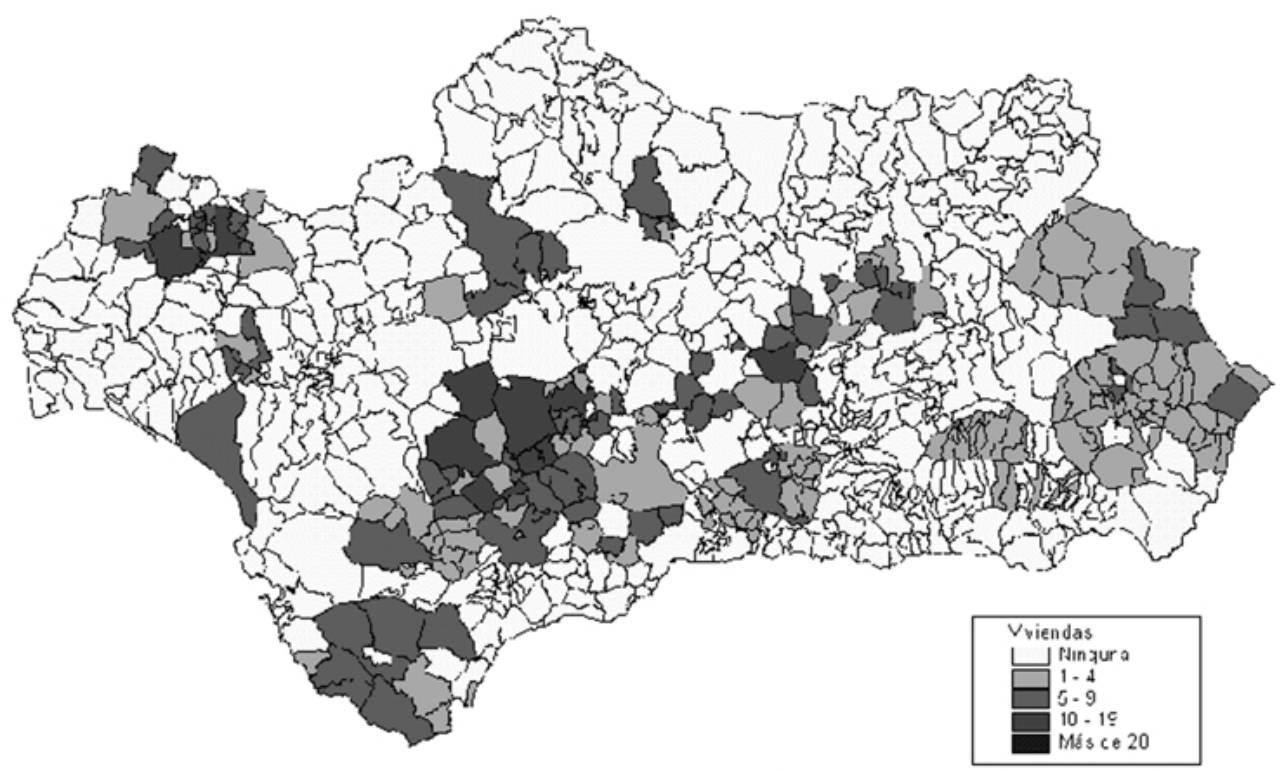

determinados oficios tradicionales (por ejemplo los barrios alfareros de la población almeriense de Nijar o el muy mermado de la población jienense de Úbeda, o el conjunto de carpinterías que conforman todo un barrio dedicado a este oficio en el pueblo de Galaroza en la provincia de Huelva), etc.

Pero incluso, entre las propias viviendas, no sólo debemos hablar de sus características en cuanto a sus peculiaridades comarcales (materiales, técnicas constructivas, distribución de espacios, vocabulario descriptivo, etc.), también hay que hacerlo de los grupos sociales que los habitaron. Y en este sentido, llamo la atención sobre una de las tipologías más desconocidas pero de extraordinario interés por múltiples razones, como es la de los medianos propietarios (mayetes, pelentrines, etc.) y la riqueza de soluciones espaciales y ornamentales a la que acudieron para testimoniar, simbólicamente, su posición intermedia en una sociedad tan polarizada como fue la andaluza.

Por último, terminaremos volviendo a hacer hincapié en algo que ya hemos dicho. Reconocida su diversidad y situación de riesgo, también hay que plantearse el qué hacer con esta arquitectura tradicional. Desde luego a toda ella hay que reconocerle su significación y valores culturales, pero las posibilidades de conservación no van a ser las mismas en todos los casos. Indudablemente buena parte de las viviendas jornaleras, por sus mismas condiciones de limitación de espacio, calidad de materiales, etc. difícilmente pueden preservarse en tanto en cuanto no reúnen las condiciones mínimas para acoger los requisitos imprescindibles que debe tener toda vivienda (hoy y en el pasado).

En este y otros casos a los que nos hemos referido, como fueran las chozas, preservar nuestro patrimonio

\section{Gráfico 7. Distribución de tipologías. Espacios de sociabilidad}

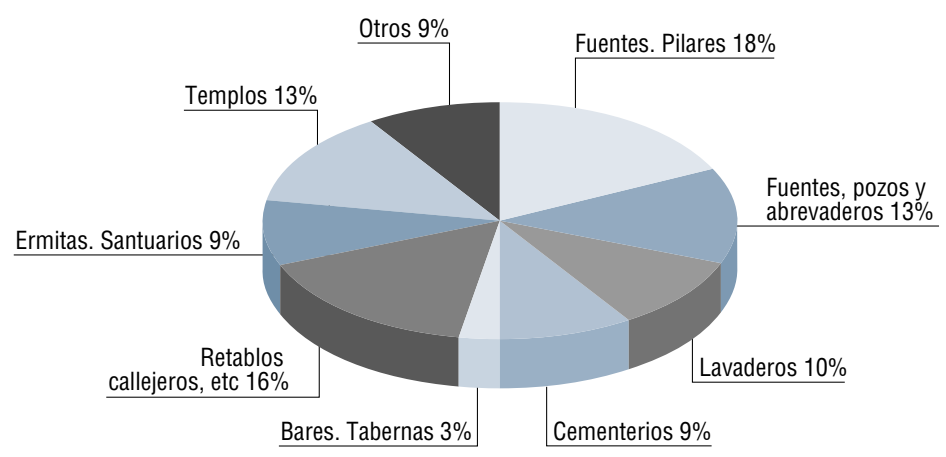

se limita (y no es poco) a testimoniar su significado histórico, como parte de una memoria colectiva donde los sectores sociales que construyeron y habitaron estas viviendas también jugaron un papel destacado. Finalmente, hay que decir que en ocasiones la ironía de la historia está encontrando nuevos "valores" incluso a la parte de nuestro patrimonio más modesto que ha llegado hasta nuestros días: en la población granadina de Montefrío, hay un verdadero empeño por conservar el último ejemplar en pie ("auténtico") que queda de las hasta no hace mucho tiempo abundantes chozas que ocupaban el barrio marginal de la parte más alta del pueblo, con la finalidad de convertirlo en museo, como el testimonio etnográfico que complemente su abundante patrimonio arqueológico, monumental y paisajístico; $y$, podríamos añadir, completar la oferta de cara al creciente turismo que acude a la localidad. 